\title{
Effects of acute tryptophan depletion on affective processing in first-degree relatives of depressive patients and controls after exposure to uncontrollable stress
}

\author{
Christine Firk • C. Rob Markus
}

Received: 8 November 2007 / Accepted: 25 February 2008 / Published online: 13 June 2008

(C) The Author(s) 2008

\begin{abstract}
Rationale Individuals with a family history of depression may be more likely to develop depression due to an innate vulnerability of their serotonergic system. However, even though serotonergic vulnerability may constitute a risk factor in the development of depression, it does not seem to be sufficient to cause a depressive episode. Based on previous data, it is suggested that stress may be a mediating factor.

Objectives This study examined the role of serotonin (5HT) in stress coping in individuals with or without a family history of depression.

Materials and methods Nineteen healthy first-degree relatives of depressive patients $(\mathrm{FH}+)$ and 19 healthy controls without a family history of depression $(\mathrm{FH}-)$ were tested in a double-blind placebo-controlled design for affective processing under acute stress exposure, following acute tryptophan depletion (ATD) or placebo.

Results Significant negative effects were found of stress on affective processing in $\mathrm{FH}^{-}$and $\mathrm{FH}+$. In addition, $\mathrm{FH}^{-}$ responded slower to positive words after stress only following ATD, whereas $\mathrm{FH}+$ responded marginally slower under stress already after placebo and before stress following ATD.

Conclusion Acute stress exposure reduces positive affective bias; supporting the role of stress as an important predecessor in the development of depression. Furthermore,
\end{abstract}

C. Firk $(\bowtie) \cdot$ C. R. Markus

Department of Clinical Psychological Science,

Faculty of Psychology, Maastricht University,

P.O. Box 616, 6200 MD Maastricht, The Netherlands

e-mail: christine.firk@psychology.unimaas.nl

C. R. Markus

Department of Neuropsychology and Psychopharmacology,

Maastricht University,

Maastricht, The Netherlands
$\mathrm{FH}+$ may be more susceptible than $\mathrm{FH}-$ to the negative effects of stress as well as to the negative effects of ATD. The results support the assumption that the 5-HT system is involved in stress resilience and may be more vulnerable in first-degree relatives of depression.

Keywords Serotonin · Major depression .

Tryptophan depletion $\cdot$ Family history $\cdot$ Stress $\cdot$ Vulnerability

\section{Introduction}

First-degree relatives of depressive patients have a two- to threefold increased risk of developing depression (Kelsoe 2005; Sullivan et al. 2000). Although environmental factors play a role, adoption and twin studies indicate that the heritability ranges between $31 \%$ and $41 \%$ (Sullivan et al. 2000). Although the neurobiological equivalent of this genetic predisposition remains unclear, the brain serotonergic system seems to be involved (Maes and Meltzer 1995; Owens and Nemeroff 1994). Evidence comes from studies reporting lower plasma serotonin (5-HT) precursor availability of tryptophan for the brain, reduced cerebrospinal fluid (CSF) concentration of the serotonin metabolite 5-hydroxyindoleacetic acid (5-HIAA) and decreased platelet 5-HT uptake in depression, suggesting diminished brain 5-HT function (Maes and Meltzer 1995; Neumeister et al. 2004b).

Acute tryptophan depletion (ATD) is commonly used to study serotonergic vulnerability (for a review, see Fusar-Poli et al. 2006; Young et al. 1985). The intervention reduces brain 5-HT through intake of a tryptophan-free amino acid mixture which reduces tryptophan (TRP) relative to the sum of the other large neutral amino acids (LNAAs) with which TRP competes for brain uptake (i.e. Fernstrom and Wurtman 1971; Gessa et al. 1974; Maes and Meltzer 1995; Moja et al. 
1991). Reduced 5-HT neurotransmission after ATD is indicated by decreased brain 5-HT synthesis and release as well as by lower concentrations of cerebrospinal fluid 5hydroxyindoleacetic acid (5-HIAA) (Carpenter et al. 1998; Nishizawa et al. 1997; Williams et al. 1999).

Acute TRP depletion is found to reverse antidepressantinduced remission (Booij et al. 2005; Delgado et al. 1990, 1999) and induces depressive symptoms in remitted depressive patients (Booij and Van der Does 2007; Hayward et al. 2005; Moreno et al. 2000, 2006; Neumeister et al. 2004a), whereas in healthy subjects, no or only modest effects are found (e.g., Benkelfat et al. 1994; Bhatti et al. 1998; Evers et al. 2005; Fusar-Poli et al. 2007; Klaassen et al. 1999; Ruhe et al. 2007). However, depressogenic effects of ATD seem to be mediated by family history for depression. Healthy subjects with a positive family history $(\mathrm{FH}+)$ of depression show greater depressed mood after ATD than healthy controls without a family history $\left(\mathrm{FH}^{-}\right)$(Benkelfat et al. 1994; Klaassen et al. 1999; Neumeister et al. 2002; Sobczak et al. 2002a; van der Veen et al. 2007). Furthermore, mood lowering effects of ATD may depend on the 5-HT transporter genotype, a gene-linked polymorphic region (5-HTTLPR) with two functional variants (Neumeister et al. 2002, 2006; Roiser et al. 2007; Walderhaug et al. 2007) that has been shown to modulate the vulnerability to depression (Caspi et al. 2003). These findings support the assumption of a 5HT vulnerability factor for depression in $\mathrm{FH}+$ increasing susceptibility to 5-HT alterations.

Even though serotonergic vulnerability may constitute a likely risk factor in the development of depression, it does not seem to be the sole contributor. Recent studies revealed that stress may be an important mediating factor. Stressful life events often precede the onset of depression (Brown et al. 1987; Heim and Nemeroff 2001; Van Praag 2004) and individuals with a genetic 5-HT vulnerability respond more readily to stressful life events with depressive feelings than individuals without a genetic vulnerability (Caspi et al. 2003). Furthermore, there is considerable evidence for complex interactions between the serotonergic system and neuroendocrine stress mechanisms (Van Praag 2004) and 5HT is involved in the initiation and termination of the stress response (Dinan 1996; Fuller 1996; Lefebvre et al. 1992). Acute stress increases brain 5-HT turnover (e.g., Davis et al. 1995; De Kloet et al. 1982; De Kloet et al. 1983) as a biological mechanism for stress adaptation (Nuller and Ostroumova 1980; Van Praag et al. 2004), whereas dysfunctional brain 5-HT is found to reduce HPA function and stress adaptation (Maes et al. 1991; Seckl and Fink 1991). In addition, brain 5-HT augmentation is found to reduce the negative effects of stress on cortisol stressresponses and depressive symptoms in healthy but stresssusceptible subjects compared to controls (Markus et al. 2000a, 2002). In accordance, Richell et al. (2005) reported that even healthy subjects are susceptible to the moodlowering effects of stress exposure following ATD.

Based on these previous findings, $\mathrm{FH}+$ individuals are thought to be prone to the negative affective effects of stress due to serotonergic vulnerability. In addition, this may even be more profound after ATD (Firk and Markus 2007).

Depression is associated with reduced attention, memory and executive functioning (Elliott et al. 1996; PaeleckeHabermann et al. 2005; Porter et al. 2003; Tavares et al. 2003); among which attention bias towards negative information has frequently been demonstrated (e.g., Lim and Kim 2005; Rinck and Becker 2005). Depressed patients respond slower to happy words compared to sad words during affective go/no-go tasks (Erickson et al. 2005; Murphy et al. 1999) and this was also observed in healthy individuals following ATD (Murphy et al. 2002).

The present study investigated whether first-degree relatives of depressive patients $(\mathrm{FH}+)$, as compared with subjects without a family history of depression $(\mathrm{FH}-)$, are more prone to the negative effects of stress exposure and TRP depletion on affective processing. Based on previous data (Murphy et al. 2002), it is hypothesized that stress, particularly after ATD, would slow down responses to positive words and that this is more pronounced in $\mathrm{FH}+$.

\section{Materials and methods}

\section{Subjects}

Maastricht University students $(n=200)$ completed a questionnaire package concerning personal details. Students reporting having at least one first-degree relative diagnosed with major depression were invited for a personal interview, as well as students reporting no first and second-degree relative with a depressive disorder. To assess $\mathrm{FH}$, all participants were interviewed by a trained psychologist with an abbreviated version of the Family History Research Diagnostic Criteria (FHRDC) (Endicott et al. 1975). In addition, participants meeting the $\mathrm{FH}+$ inclusion criteria were asked whether relatives could be contacted for confirmation.

Nineteen healthy first-degree relatives of depressive patients $(\mathrm{FH}+)$ and 19 healthy controls without a family history of depression ( $\mathrm{FH}-$ ) were selected for the experiment. A structured psychiatric interview (MINI) (Sheehan et al. 1994) was carried out to exclude psychiatric disorders. Furthermore, the Symptom Checklist SCL-90 (Arrindell and Ettema 1986) and the Beck Depression Inventory (BDI) (Beck et al. 1961) were filled in to verify the absence of depressive and general psychopathologic symptomatology. The $\mathrm{FH}-$ group and the $\mathrm{FH}+$ group did not differ with respect to sex, age, BMI and BDI, and SCL-90 scores (all 
$p>0.05)$. Demographic characteristics are presented in Table 1.

Participants were excluded if they reported chronic and current illness; history of psychiatric or medical illness; medication use; metabolic, hormonal, or intestinal diseases; irregular diets; or deviant eating habits and excessive alcohol or drug use. Participants' health was checked with standardized medical questionnaires that were evaluated by a trained doctoral-level psychologist under the supervision of a medical doctor.

Participants included in the study revealed normal bodymass indexes (BMI, between 19 and $26 \mathrm{~kg} / \mathrm{m}^{2}$ ) were nonsmokers and were requested not to use alcohol or any kind of drugs before and during the study. Inclusion criteria for $\mathrm{FH}+$ were the presence of at least one first-degree relative with major depression according to the DSM-IV criteria, whereas inclusion criteria for $\mathrm{FH}^{-}$include absence of a first- or second-degree relative with major depression.

The study was approved by the Medical Ethics Committee of the Academic Hospital Maastricht and complied with the requirements of the European Council of Good Clinical Practice (GCP) adopted by the 52nd World Medical Association General Assembly, Edinburgh, Scotland (October, 2000). All subjects gave their informed consent and were paid 125 Euros for participation.

\section{Design}

A placebo-controlled, double-blind, crossover design was used. During two experimental sessions, subjects were monitored for affective processing before and after acute stress exposure either following intake of a TRP-free (ATD) or a TRP-containing placebo (PLC) amino acid mixture. The order of presentation of the ATD and PLC condition was counterbalanced within groups and both experimental sessions were separated by at least 1 week. Female subjects were tested in the follicular phase of their menstrual cycle or when actually taking oral contraceptives.

Table 1 Demographic characteristics of the $\mathrm{FH}+$ group and $\mathrm{FH}-$ group

\begin{tabular}{lcc}
\hline & FH+ & FH- \\
\hline Women & 15 & 14 \\
Men & 4 & 5 \\
Age & $20.5(2.1)$ & $22.1(3.6)$ \\
BMI & $21.7(2.2)$ & $23.1(2.5)$ \\
SCL-90 & $19.9(17.9)$ & $26.4(23.6)$ \\
BDI & $3.6(3.6)$ & $5.4(4.2)$ \\
\hline
\end{tabular}

Values are mean (SD).
Procedure

Eligible participants attended a briefing at Maastricht University to receive information about the study and to be scheduled for the experiment.

On each experimental morning, two subjects arrived at the laboratory at 08:30 am and 10:00 am, respectively. Subjects fasted overnight; only water or tea without sugar was permitted. After arrival, a first blood sample was taken followed by a first version of the affective go/no-go task to make subjects familiar with the test condition. Then, a first measurement of vegetative side effects was conducted followed by administration of the amino acid mixture $\left(t_{0}\right)$. Four and a half hours later $\left(t_{4.5}\right)$, a second blood sample was taken followed by a second measure of vegetative side effects. Then $\left(t_{5}\right)$ participants conducted a second version of the affective go/no-go task followed by the stress task. After completion of the stress task, a third version of the affective go/no-go task was administered.

Between intake of the amino acid mixture and exposure to laboratory tasks, the subjects were able to study or to read magazines in a separated private room. They had free access to water and decaffeinated tea. Two hours after administration of the amino acid mixture, they received a standardized protein-poor lunch as previously used in ATD studies (Riedel et al. 1999; Sobczak et al. 2002a, b). At the end of each test day, subjects received a high protein snack and bananas, which are natural sources of L-tryptophan to facilitate a quick recovery from possible negative effects of ATD.

\section{Acute tryptophan depletion}

A reduction in brain 5-HT was accomplished by ATD through the use of a tryptophan-free collagen-protein (CP) amino acid drink (Blokland et al. 2004; Evers et al. 2005). To obtain a drinkable mixture, $100 \mathrm{~g}$ of the protein powder was mixed with $200 \mathrm{ml}$ of tap water and $20 \mathrm{ml}$ syrup. The placebo mixture was identical in composition but $1.2 \mathrm{~g} \mathrm{l-}$ TRP (Sigma, Zwijndrecht; The Netherlands) was added. See Table 2 for the amino acid composition of the different conditions (Evers et al. 2005).

This ATD method differs from the classic methodology by including a gelatin-based hydrolyzed CP that contains the entire range of amino acids (except for L-TRP) in the form of peptides. After administration, these peptides are decomposed into amino acids and the mechanism of depletion is identical to the classic ATD method (Blokland et al. 2004; Evers et al. 2005).

\section{Stress exposure}

The Markus-Peters computerized mental arithmetic task (MPA) was used as an uncontrollable stress situation. 
Table 2 Composition (grams) of the gelatin-based protein (all values are $\mathrm{g}$ per $100 \mathrm{~g}$ of each mixture)

\begin{tabular}{lcc}
\hline & ATD & PLC \\
\hline Phenylalanine & 1.9 & 1.9 \\
Tyrosine & 0.4 & 0.4 \\
Valine & 2.1 & 2.1 \\
Leucine & 3 & 3 \\
Isoleucine & 1.4 & 1.4 \\
Tryptophan & $\mathbf{0 . 1}$ & $\mathbf{1 . 3}$ \\
Serine & 3.1 & 3.1 \\
Glycine & 22.5 & 22.5 \\
Histidine & 0.5 & 0.5 \\
Arginine & 8.8 & 8.8 \\
Threonine & 1.1 & 1.1 \\
Alanine & 9.3 & 9.3 \\
Proline & 13.3 & 13.3 \\
Methionine & 0.6 & 0.6 \\
Cystein & 0.2 & 0.2 \\
Lysine & 3.6 & 3.6 \\
Hydroxyproline & 12.1 & 12.1 \\
Hydroxylysine & 1.4 & 1.4 \\
Aspartic acid + asparagines & 9.3 & 9.3 \\
Glutamic acid + glutamine & 5.2 & 5.2 \\
\hline
\end{tabular}

Subjects were given eight successive 1-min trials during which they had to solve a specific number of multiple choice mental arithmetic problems (the criterion) under time constraints, while exposed to continuous 75,80 , or $85 \mathrm{~dB}$ industrial noise presented through headphones. They were led to believe that the intensity of the noise depended on their performance; if they failed the criterion, noise intensity was chosen by the computer during the next trial; if they met the criterion, they could choose the intensity of the noise. In fact, the criterion was always set at one sum above what subjects could manage as calculated from the average time per sum needed on previous trials. This task has been demonstrated to induce psychological and physiological stress (Markus et al. 1998, 2000a, b; Peters et al. 1998).

\section{Affective go/no-go paradigm}

A modified version of the affective go/no-go task described by Murphy et al. (1999) was used to detect affective attentional bias. In this task, happy and sad words are presented on the screen one-by-one for $300 \mathrm{~ms}$, followed by an interstimulus interval of $900 \mathrm{~ms}$ during which participants must make or withhold a response depending on word valence. The task comprised two practice and 12 experimental blocks; each containing nine happy words and nine sad words. Subjects were instructed to respond either to happy or sad words before each block and to respond as quickly as possible.
Every two blocks, the targets and the distractors changed; words that were previously targets became distractors and vice versa (SSHHSSHHSSHHSS or HHSSHHSSHHSSHH). Due to this arrangement, shift blocks and non-shift blocks could be studied. The 27 happy words and 27 sad words were derived from previous studies (e.g., Lim and Kim 2005; Rinck and Becker 2005) and were matched on frequency, word length, and valence. Every word was presented twice as target and twice as distractor; once in a shift block and once in a non-shift block.

Vegetative side effects

In order to measure possible side effects of the amino acid mixtures, a list (five-point scales) of 10 vegetative side effects was completed before and $4.5 \mathrm{~h}\left(t_{4.5}\right)$ after intake. The list contained the following items: feeling cold, feeling hot, dizziness, transpiration, bulled vision, nausea, palpitations, dry mouth, and abdominal complaints.

\section{Biochemical analyses}

Blood samples were collected in $5 \mathrm{ml}$ vacutainer tubes containing sodium heparine for amino acids and were centrifuged at $5,000 \mathrm{rpm}$ for $10 \mathrm{~min}$ at $4^{\circ} \mathrm{C}$. Subsequently, the supernatants were directly stored at $-80^{\circ} \mathrm{C}$ until analysis. Before storage, the supernatant for amino acid determination $(100 \mu \mathrm{l})$ were mixed with $4 \mathrm{mg}$ sulfasalicylic acid. Analyses were conducted with HPLC, making use of a 2-3 $\mu \mathrm{m}$ Bischof Spherisorb ODS II column. The plasma tryptophan ratio was calculated by dividing the tryptophan concentration by the sum of the other large neutral amino acids, i.e. valine, isoleucine, leucine, tyrosine, and phenylalanine.

\section{Statistical analysis}

The main research questions were analyzed by repeated measures analyses of variance (ANOVAs) by using the General Linear Model (GLM: SPSS 12.0 for Windows) with one between-subjects factor family history ( $\mathrm{FH}+$ versus $\mathrm{FH}^{-}$) and the within-subjects factors treatment (ATD versus PLC), stress (pre-stress versus post-stress), or time ( $t_{0}$ versus $t_{4.5}$ ) on the several dependent measures. Furthermore, in the analyses of the affective go/no go performance target valence (sad versus happy) and shift (shift versus non-shift condition) were added as withinsubjects factors. Although we counterbalanced for order and gender, these factors were preliminary taken as covariates. However, since none of these factors contributed to (or changed) any of our findings, order of treatment and gender were left out of the final analyses. All statistics are evaluated at a significance level of 5\% (two-tailed). 


\section{Results}

Plasma amino acids (TRP:LNAA ratio)

Repeated measures analysis of variance with $\mathrm{FH}\left(\mathrm{FH}^{-}\right.$ versus $\mathrm{FH}+$ ) as between-subjects factor and treatment (ATD versus PLC) and time ( $t_{0}$ versus $\left.t_{4.5}\right)$ as within-subjects factors were carried out for total plasma TRP concentrations and for the TRP:LNAA ratio. For TRP concentrations, a significant treatment $\times$ time interaction was found $[F$ $(1,36)=156.57, p<0.001]$ reflecting a decrease from $t_{0}$ to $t_{4.5}$ by $62 \%$ after ATD and an increase from $t_{0}$ to $t_{4.5}$ by $13 \%$ after PLC administration (see Fig. 1). Analysis of the plasma TRP:LNAA ratio revealed a significant treatment $\times$ time interaction $[F(1,36)=158.77, p<0.001]$. As indicated in Fig. 1, there was a $65 \%$ decline in plasma TRP:LNAA after ATD and an increase from $t_{0}$ to $t_{4.5}$ by $8 \%$ after PLC. No other main or interaction effects were found including $\mathrm{FH}$.

\section{Vegetative side effects}

Repeated measures analysis of variance with $\mathrm{FH}\left(\mathrm{FH}^{-}\right.$ versus $\mathrm{FH}+$ ) as between-subjects factor and treatment (ATD versus PLC) and time ( $t_{0}$ versus $\left.t_{4.5}\right)$ as within-subjects factors on the total score of vegetative side effects did not reveal any significant main or interaction effects.
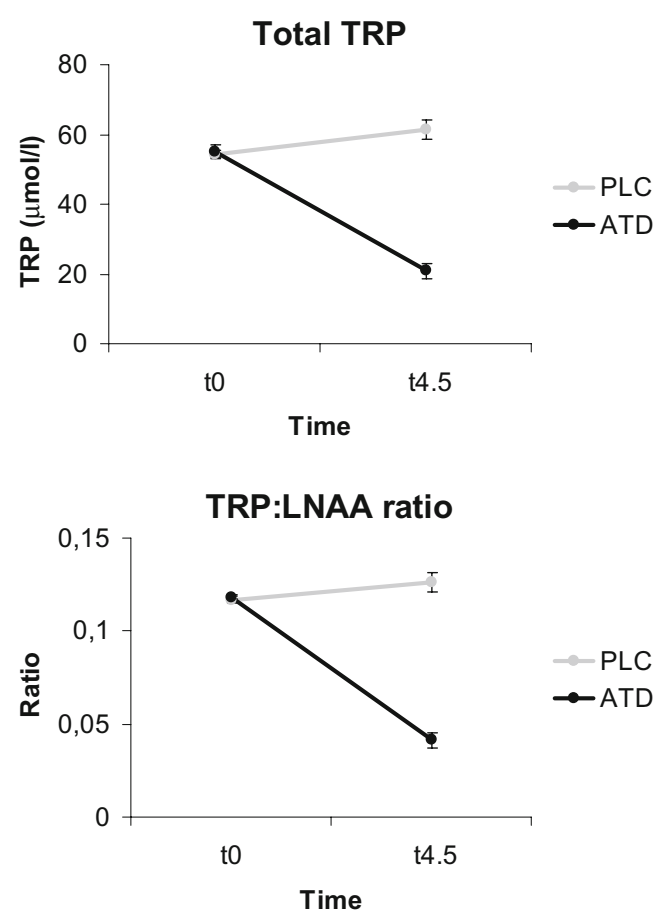

Fig. 1 Plasma total tryptophan concentrations and TRP/LNAA ratio for the ATD and PLC condition
Affective go/no-go performance

Mean values and standard deviations are presented in Table 3. Repeated measures ANOVAs were carried out with $\mathrm{FH}(\mathrm{FH}-$ versus $\mathrm{FH}+$ ) as between-subjects factor and treatment (ATD versus PLC), target valence (sad versus happy), shift (shift versus non-shift condition), and stress (pre-stress versus post-stress) as within-subjects factors on reaction time, errors, and omissions. To investigate changes from baseline to pre-stress (to explore acute effects of treatment), we repeated the statistical analyses and replaced the WS factor stress (pre-stress versus post-stress) with the WS factor time (baseline versus pre-stress). However, as we did not find any effect of treatment, these analyses are not described. Furthermore, no baseline differences were found between test days.

Reaction Time Analysis of reaction time (RT) data revealed a significant valence $\times$ stress interaction $[F(1,36)=5.42, p=$ $0.026]$ reflecting increased RTs for happy words post-stress compared to pre-stress $[t(37)=2.09, p<0.0 .043]$ but not for sad words $[t(37)=1.39, p=0.17]$ (Fig. 2). However, this interaction was qualified by a significant 5-way $\mathrm{FH} \times$ treatment $\times$ stress $\times$ valence $\times$ shift interaction $[F(1,36)=$ 3.99, $p=0.05]$. Further analysis for the shift and non-shift condition separately revealed a significant $\mathrm{FH} \times$ treatment $\times$ stress $\times$ valence interaction for the non-shift condition only $[F(1,36)=6.36, p=0.016]$. In the non-shift condition, there was a significant $\mathrm{FH} \times$ treatment $\times$ stress interaction for happy words only $[F(1,36)=6.69, p=0.014])$. As visualized in Fig. 3, the FH- group showed slower RTs post-stress compared to pre-stress only following ATD $[t(18)=2.57, p=$ $0.019]$ but not after PLC $[t(18)<1]$, whereas the FH+ group showed slower RTs post-stress compared to pre-stress independent of treatment and slower RTs already following ATD (before stress onset). These latter changes in the $\mathrm{FH}+$ group, however, did not approach significance by further post-hoc testing ( $P$ between 0.07 and 0.11 ).

Errors Analysis of error data revealed a main effect of shift $[F(1,36)=18.81, p<0.001]$; indicating significant more errors during shift blocks compared to the non-shift blocks. Analysis also revealed a main effect of stress $(F(1,36)=$ 8.42, $p=0.006$ ), indicating a decrease in the number of errors post-stress compared to pre-stress. There were no effects of FH, treatment, or valence.

Omissions Analysis of omission data revealed a significant stress by valence interaction $[F(1,36)=7.57, p=0.009]$, indicating that significant more omissions were made prestress compared to post-stress for happy words $[t(37)=2.31$, $p=0.027]$ but not for sad words $[t(37)=1.16, p=0.25]$. There were no effects of FH or treatment. 
Table 3 Affective go/no go data

\begin{tabular}{|c|c|c|c|c|c|c|c|c|c|}
\hline & & \multicolumn{4}{|l|}{$\mathrm{FH}+$} & \multicolumn{4}{|l|}{ FH- } \\
\hline & & \multicolumn{2}{|l|}{ PLC } & \multicolumn{2}{|l|}{ ATD } & \multicolumn{2}{|l|}{ PLC } & \multicolumn{2}{|l|}{ ATD } \\
\hline & & Pre-stress & Post-stress & Pre-stress & Post-stress & Pre-stress & Post-stress & Pre-stress & Post-stress \\
\hline \multirow[t]{3}{*}{ Happy shift } & RTs & $512(78)$ & $500(79)$ & 487 (98) & 497 (72) & 497 (61) & $514(55)$ & $497(53)$ & $504(60)$ \\
\hline & Errors & $2.8(2.4)$ & $2.2(1.8)$ & $3.2(2.6)$ & $3.3(3.8)$ & $3.1(2.6)$ & $2.7(2.2)$ & $3.2(2.6)$ & $3.3(3.8)$ \\
\hline & Omissions & $2.4(2.8)$ & $2.4(2.6)$ & $3.3(4.6)$ & $2.3(3.0)$ & $1.3(1.3)$ & $1.2(2.0)$ & $1.1(1.2)$ & $1.3(2.5)$ \\
\hline \multirow[t]{3}{*}{ Happy non-shift } & RTs & $486(77)$ & $522(69)$ & $521(46)$ & $518(74)$ & $496(61)$ & $492(51)$ & $489(58)$ & $520(59)$ \\
\hline & Errors & $2.5(1.9)$ & $1.7(1.2)$ & $1.8(1.6)$ & $2.6(2.1)$ & $2.2(1.8)$ & $1.9(2.5)$ & $2.1(2.3)$ & $2.1(2.0)$ \\
\hline & Omissions & $3.1(3.5)$ & $1.6(1.7)$ & $1.7(1.4)$ & $1.9(2.7)$ & $1.7(2.1)$ & $1.6(1.4)$ & $1.6(2.1)$ & $0.8(1.1)$ \\
\hline \multirow[t]{3}{*}{ Sad shift } & RTs & $514(72)$ & $499(63)$ & $511(57)$ & $489(95)$ & $508(98)$ & $506(46)$ & $522(58)$ & $504(59)$ \\
\hline & Errors & $3.2(2.7)$ & $2.2(2.7)$ & $3.5(4.4)$ & $2.7(2.9)$ & $2.4(2.1)$ & $1.4(1.6)$ & $2.4(2.5)$ & $2.4(1.9)$ \\
\hline & Omissions & $1.9(2.9)$ & $2.1(2.4)$ & $1.9(3.0)$ & $2.7(4.0)$ & $1.4(2.1)$ & $1.1(1.20$ & $0.5(0.8)$ & $1.4(2.2)$ \\
\hline \multirow[t]{3}{*}{ Sad non-shift } & RTs & $519(52)$ & $510(65)$ & $517(51)$ & $507(42)$ & $512(48)$ & $526(58)$ & $514(53)$ & $515(57)$ \\
\hline & Errors & $2.5(2.3)$ & $2.2(1.6)$ & $2.0(1.6)$ & $2.1(2.5)$ & $1.5(1.7)$ & $1.6(1.7)$ & $2.3(1.9)$ & 1.7 (1.9) \\
\hline & Omissions & $1.7(1.9)$ & $1.6(2.1)$ & $1.7(1.6)$ & $2.0(2.6)$ & $0.8(1.1)$ & $0.8(1.2)$ & $1.0(1.4)$ & $1.1(1.2)$ \\
\hline
\end{tabular}

Values represent mean (SD)

\section{Discussion}

The goal of the present study was to assess affective processing in individuals with a positive $(\mathrm{FH}+)$ or negative $(\mathrm{FH}-)$ family history of depression following ATD or placebo under acute stress exposure. Tryptophan depletion lowered the plasma TRP:LNAA ratio by $65 \%$, which is comparable with previous studies using the collagenprotein (Evers et al. 2005) or classic ATD mixture (Van der Does 2001).

Although psychological or physiological stress responses were not measured in the current study, significant stressinduced emotional, cognitive, hormonal, and electrophysiological changes have been reported with the MPA task (e.g., Markus et al. 2002; Peters et al. 1998). Furthermore, reaction times significantly decreased after the stress task, further supporting that stress was successfully induced in the current study.

Analysis of affective processing revealed a stress by valence interaction reflecting reduced responsiveness to happy words after acute stress exposure. Previous findings already demonstrated slowed or diminished responses to happy words in depressed patients compared to healthy controls (Deveney and Deldin 2004; Erickson et al. 2005; Murphy et al. 1999), which may reflect lower mood and subsequent increased interference from sad distractors. Current findings indicate that a positive affective bias normally found in healthy individuals may also be diminished by acute stress exposure, which may be due to a stress-induced lowering of mood (van der Veen et al. 2007). This further supports the hypothesis of stress as an important predecessor in the development of depression (Brown et al. 1987; Heim and Nemeroff 2001; Van Praag
2004). Current data further suggest that the negative effects of stress on (reducing) positive affective bias may depend on family history of depression and may be influenced by ATD and task-shifting. The $\mathrm{FH}^{-}$group showed stressinduced slowed responses to happy words in non-shift blocks only following ATD, whereas the $\mathrm{FH}+$ group roughly seemed to exhibit such reductions already after ATD (which was not found after PLC) as well as after stress following PLC.

The present findings suggest that acute stress induces a negative affective bias and that $\mathrm{FH}-$ subjects may be more stress-resilient than $\mathrm{FH}+$ subjects and may become susceptible to stress especially after ATD. Interestingly, although task shifting requires more cognitive flexibility (e.g., Monsell 2003), the negative affective bias (slowed

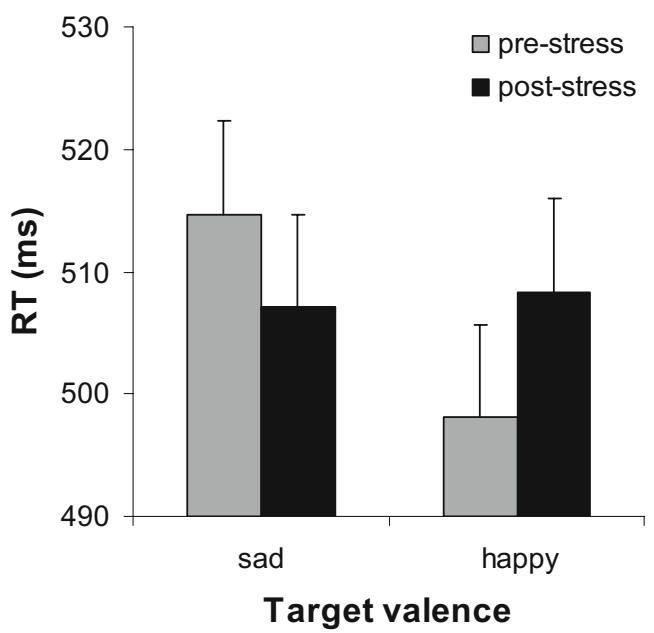

Fig. 2 Mean RTs (SE) for happy and sad targets before and after stress exposure collapsed over treatment and family history 

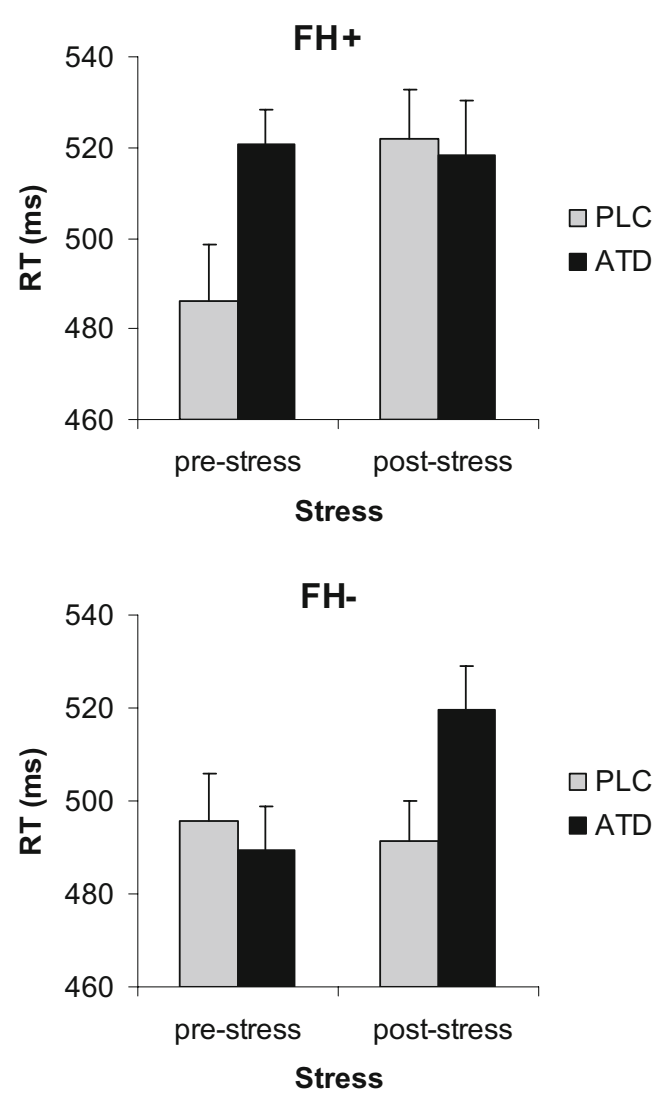

Fig. 3 Mean RTs (SE) for happy non-shift targets for the FH+ group and the $\mathrm{FH}^{-}$group

responses to happy words following stress and ATD) could only be seen for the non-shift blocks but not for the shift blocks. Although hypothetical, the increased negative affective bias following stress as well as ATD may be less profound the more attention or alertness is required (shift blocks) and may be increased in situations in which less attention is required (non-shift blocks). Previous ATD studies with healthy subjects revealed mixed results; either reporting negative affective bias following ATD for shift and non-shift blocks (Murphy et al. 2002) or no effects at all (Roiser et al. 2007; Rubinsztein et al. 2001). Current data may explain these inconsistent findings by the mediating influence of stress. Individuals with a family history of depression may already be prone to the negative effects of ATD and may also be more negatively affected by stress in the absence of ATD. These findings should of course be interpreted with caution since they appear to be rather modest (also depending on task-shifting and valence) and do not remain significant after repeated post-hoc testing in the separated small $\mathrm{FH}+$ group. Yet, they nicely comply with - and elaborate on - previous findings and suggestions of an innate 5-HT vulnerability in FH+ (Benkelfat et al. 1994; Klaassen et al. 1999; Sobczak et al. 2002a, b). Hence, serotonin plays an important role in stress coping, and clear interactions appear between 5-HT and the neuroendocrine stress system (Porter et al. 2004). Acute stress increases 5HT neurotransmission (Davis et al. 1995; De Kloet et al. 1982, 1983), which promotes stress adaptation by mediating negative feedback control of cortisol on the HPA axis (Nuller and Ostroumova 1980; Van Praag 2004). Increased 5-HT under stress will be diminished after ATD and subsequently may increase stress vulnerability. Richell et al. (2005) reported greater negative mood after stress in healthy subjects following ATD that was attributed to reduced function of the 5-HT-mediated resilience system and subsequent enhanced stress susceptibility. In the studies of Markus et al. (2000a, 2002), 5-HT augmentation was found to enhance resilience to stress only in chronically stressed (healthy) subjects probably by compensatory stress-induced 5-HT receptor sensitization. Whereas 5-HT challenge may particularly improve stress coping in 5-HT vulnerable subjects, ATD may lower stress coping also in non-vulnerable subjects due to a drastic depletion in brain TRP and subsequent 5-HT function.

One limitation of the present study is that we did not include mood changes. It has been suggested that ATDinduced changes in affective processing are mediated by reduced mood (van der Veen et al. 2007) which may also hold for stress-induced changes. However, it remains questionable whether ATD- or stress-induced changes in affective processing are necessarily mediated by subjective mood changes. Murphy et al. (2002) reported a negative affective bias in the affective go/no-go following ATD in healthy volunteers but did not find any changes in mood. Therefore, measuring affective processing may be a more sensitive method to measure stress- or ATD-related changes. Yet, in further studies it would, nevertheless, be interesting to include changes in explicit mood experiences as an additional affective measure. A second limitation may be that we did not contact family members to confirm diagnoses; however, participants were interviewed by a trained psychologist and to increase reliability, all participants were asked whether relatives could be contacted to confirm diagnoses.

In conclusion, acute stress exposure reduces positive affective bias supporting the role of stress as an important predecessor in the development of depression. However, these negative effects of stress may depend on family history of depression: FH+ may be more susceptible to the negative effects of stress and ATD on affective processing than $\mathrm{FH}^{-}$. Nevertheless, the tentative explanation that $\mathrm{FH}+$ is more prone to stress and ATD due to an innate serotonergic vulnerability merits further research.

Disclosure/conflicts of interest All authors ensure the integrity of the work and none of them has any direct or indirect financial or personal interests, or conflicts of interest, to the subject matter of the manuscript. 
Open Access This article is distributed under the terms of the Creative Commons Attribution Noncommercial License which permits any noncommercial use, distribution, and reproduction in any medium, provided the original author(s) and source are credited.

\section{References}

Arrindell WA, Ettema JHM (1986) SCL-90. Een multidimensionel psychopathologie indicator [SCL-90. A multidimensional indicator of psychopathology]. Swets en Zeitlinger, Swets en Zeitlinger

Beck AT, Ward CH, Mendelson M, Mock J, Erbaugh J (1961) An inventory for measuring depression. Arch Gen Psychiatry 4:561-571

Benkelfat C, Ellenbogen MA, Dean P, Palmour RM, Young SN (1994) Mood-lowering effect of tryptophan depletion. Enhanced susceptibility in young men at genetic risk for major affective disorders. Arch Gen Psychiatry 51:687-697

Bhatti T, Gillin JC, Seifritz E, Moore P, Clark C, Golshan S, Stahl S, Rapaport M, Kelsoe J (1998) Effects of a tryptophan-free amino acid drink challenge on normal human sleep electroencephalogram and mood. Biol Psychiatry 43:52-59

Blokland A, Lieben C, Deutz NEP, Schmitt J (2004) Acute tryptophan depletion: comparing the effects of an amino acid mixture with a gelatin-based protein in man and rats. Curr Top Nutraceutical Res 2:161-169

Booij L, Van der Does AJ (2007) Cognitive and serotonergic vulnerability to depression: convergent findings. J Abnorm Psychology 116:86-94

Booij L, van der Does AJ, Haffmans PM, Spinhoven P, McNally RJ (2005) Acute tryptophan depletion as a model of depressive relapse: behavioural specificity and ethical considerations. Br J Psychiatry 187:148-154

Brown GW, Bifulco A, Harris TO (1987) Life events, vulnerability and onset of depression: some refinements. Br J Psychiatry 150:30-42

Carpenter LL, Anderson GM, Pelton GH, Gudin JA, Kirwin PD, Price LH, Heninger GR, McDougle CJ (1998) Tryptophan depletion during continuous CSF sampling in healthy human subjects. Neuropsychopharmacology 19:26-35

Caspi A, Sugden K, Moffitt TE, Taylor A, Craig IW, Harrington H, McClay J, Mill J, Martin J, Braithwaite A, Poulton R (2003) Influence of life stress on depression: moderation by a polymorphism in the 5-HTT gene. Science 301:386-389

Davis S, Heal DJ, Stanford SC (1995) Long-lasting effects of an acute stress on the neurochemistry and function of 5-hydroxytryptaminergic neurones in the mouse brain. Psychopharmacology (Berl) 118:267-272

De Kloet ER, Kovacs GL, Szabo G, Telegdy G, Bohus B, Versteeg DH (1982) Decreased serotonin turnover in the dorsal hippocampus of rat brain shortly after adrenalectomy: selective normalization after corticosterone substitution. Brain Res 239:659-663

De Kloet ER, Versteeg DH, Kovacs GL (1983) Aldosterone blocks the response to corticosterone in the raphe-hippocampal serotonin system. Brain Res 264:323-327

Delgado PL, Charney DS, Price LH, Aghajanian GK, Landis H, Heninger GR (1990) Serotonin function and the mechanism of antidepressant action. Reversal of antidepressant-induced remission by rapid depletion of plasma tryptophan. Arch Gen Psychiatry 47:411-418

Delgado PL, Miller HL, Salomon RM, Licinio J, Krystal JH, Moreno FA, Heninger GR, Charney DS (1999) Tryptophan-depletion challenge in depressed patients treated with desipramine or fluoxetine: implications for the role of serotonin in the mechanism of antidepressant action. Biol Psychiatry 46:212-220
Deveney CM, Deldin PJ (2004) Memory of faces: a slow wave ERP study of major depression. Emotion 4:295-304

Dinan TG (1996) Serotonin and the regulation of hypothalamicpituitary-adrenal axis function. Life Sci 58:1683-1694

Elliott R, Sahakian BJ, McKay AP, Herrod JJ, Robbins TW, Paykel ES (1996) Neuropsychological impairments in unipolar depression: the influence of perceived failure on subsequent performance. Psychol Med 26:975-989

Endicot J, Andreasen NC, Spitzer RL (1975) Family history research diagnostic criteria. Biometrics Research, New York State Psychiatric Institute

Erickson K, Drevets WC, Clark L, Cannon DM, Bain EE, Zarate CA Jr, Charney DS, Sahakian BJ (2005) Mood-congruent bias in affective go/no-go performance of unmedicated patients with major depressive disorder. Am J Psychiatry 162:2171-2173

Evers EA, Tillie DE, van der Veen FM, Lieben CK, Jolles J, Deutz NE, Schmitt JA (2005) Effects of a novel method of acute tryptophan depletion on plasma tryptophan and cognitive performance in healthy volunteers. Psychopharmacology (Berl) 178:92-99

Fernstrom JD, Wurtman RJ (1971) Brain serotonin content: physiological dependence on plasma tryptophan levels. Science 173:149-152

Firk C, Markus CR (2007) Review: serotonin by stress interaction: a susceptibility factor for the development of depression? J Psychopharmacol 21:538-544

Fuller RW (1996) Serotonin receptors involved in regulation of pituitary-adrenocortical function in rats. Behav Brain Res 73:215-219

Fusar-Poli P, Allen P, McGuire P, Placentino A, Cortesi M, Perez J (2006) Neuroimaging and electrophysiological studies of the effects of acute tryptophan depletion: a systematic review of the literature. Psychopharmacology (Berl) 188:131-143

Fusar-Poli P, Allen P, Lee F, Surguladze S, Tunstall N, Fu CH, Brammer MJ, Cleare AJ, McGuire PK (2007) Modulation of neural response to happy and sad faces by acute tryptophan depletion. Psychopharmacology (Berl) 193:31-44

Gessa GL, Biggio G, Fadda F, Corsini GU, Tagliamonte A (1974) Effect of the oral administration of tryptophan-free amino acid mixtures on serum tryptophan, brain tryptophan and serotonin metabolism. J Neurochem 22:869-870

Hayward G, Goodwin GM, Cowen PJ, Harmer CJ (2005) Low-dose tryptophan depletion in recovered depressed patients induces changes in cognitive processing without depressive symptoms. Biol Psychiatry 57:517-524

Heim C, Nemeroff CB (2001) The role of childhood trauma in the neurobiology of mood and anxiety disorders: preclinical and clinical studies. Biol Psychiatry 49:1023-1039

Kelsoe JR (2005) Mood disoders: genetics. In: Sadock BJ, Sadock VA (eds) Kaplan \& Sadock's comprehensive textbook of psychiatry. Lippincott Williams \& Wilkins, Philadelphia, pp 1582-1593

Klaassen T, Riedel WJ, van Someren A, Deutz NE, Honig A, van Praag HM (1999) Mood effects of 24-hour tryptophan depletion in healthy first-degree relatives of patients with affective disorders. Biol Psychiatry 46:489-497

Lefebvre H, Contesse V, Delarue C, Feuilloley M, Hery F, Grise P, Raynaud G, Verhofstad AA, Wolf LM, Vaudry H (1992) Serotonin-induced stimulation of cortisol secretion from human adrenocortical tissue is mediated through activation of a serotonin4 receptor subtype. Neuroscience 47:999-1007

Lim SL, Kim JH (2005) Cognitive processing of emotional information in depression, panic, and somatoform disorder. J Abnorm Psychol 114:50-61

Maes M, Meltzer HY (1995) The serotonin hypothesis of major depression. In: Bloom FE, Kupfer DJ (eds) Psychopharmacology: The fourth generation of progress. Raven, New York, pp 933-944

Maes M, Minner B, Suy E (1991) The relationships between the availability of L-tryptophan to the brain, the spontaneous HPA- 
axis activity, and the HPA-axis responses to dexamethasone in depressed patients. Amino Acids 1:57-65

Markus CR, Panhuysen G, Tuiten A, Koppeschaar H, Fekkes D, Peters ML (1998) Does carbohydrate-rich, protein-poor food prevent a deterioration of mood and cognitive performance of stress-prone subjects when subjected to a stressful task? Appetite 31:49-65

Markus CR, Olivier B, Panhuysen GE, Van Der Gugten J, Alles MS, Tuiten A, Westenberg HG, Fekkes D, Koppeschaar HF, de Haan EE (2000a) The bovine protein alpha-lactalbumin increases the plasma ratio of tryptophan to the other large neutral amino acids, and in vulnerable subjects raises brain serotonin activity, reduces cortisol concentration, and improves mood under stress. Am J Clin Nutr 71:1536-1544

Markus CR, Panhuysen G, Tuiten A, Koppeschaar H (2000b) Effects of food on cortisol and mood in vulnerable subjects under controllable and uncontrollable stress. Physiol Behav 70:333342

Markus CR, Olivier B, de Haan EH (2002) Whey protein rich in alphalactalbumin increases the ratio of plasma tryptophan to the sum of the other large neutral amino acids and improves cognitive performance in stress-vulnerable subjects. Am J Clin Nutr 75:1051-1056

Moja EA, Rocchi E, Benedetti F, Paolillo F, Casalgrandi G, Ponz de Leon M (1991) Decrease in plasma tryptophan after a tryptophan-free amino acid solution. A comparison between cirrhotic and control subjects. Life Sci 48:409-418

Monsell S (2003) Task switching. Trends Cogn Sci 7:134-140

Moreno FA, Heninger GR, McGahuey CA, Delgado PL (2000) Tryptophan depletion and risk of depression relapse: a prospective study of tryptophan depletion as a potential predictor of depressive episodes. Biol Psychiatry 48:327-329

Moreno FA, McGahuey CA, Freeman MP, Delgado PL (2006) Sex differences in depressive response during monoamine depletions in remitted depressive subjects. J Clin Psychiatry 67: $1618-1623$

Murphy FC, Sahakian BJ, Rubinsztein JS, Michael A, Rogers RD, Robbins TW, Paykel ES (1999) Emotional bias and inhibitory control processes in mania and depression. Psychol Med 29:1307-1321

Murphy FC, Smith KA, Cowen PJ, Robbins TW, Sahakian BJ (2002) The effects of tryptophan depletion on cognitive and affective processing in healthy volunteers. Psychopharmacology (Berl) $163: 42-53$

Neumeister A, Konstantinidis A, Stastny J, Schwarz MJ, Vitouch O, Willeit M, Praschak-Rieder N, Zach J, de Zwaan M, Bondy B, Ackenheil M, Kasper S (2002) Association between serotonin transporter gene promoter polymorphism (5HTTLPR) and behavioral responses to tryptophan depletion in healthy women with and without family history of depression. Arch Gen Psychiatry 59:613-620

Neumeister A, Nugent AC, Waldeck T, Geraci M, Schwarz M, Bonne O, Bain EE, Luckenbaugh DA, Herscovitch P, Charney DS, Drevets WC (2004a) Neural and behavioral responses to tryptophan depletion in unmedicated patients with remitted major depressive disorder and controls. Arch Gen Psychiatry 61:765-773

Neumeister A, Young T, Stastny J (2004b) Implications of genetic research on the role of the serotonin in depression: emphasis on the serotonin type $1 \mathrm{~A}$ receptor and the serotonin transporter. Psychopharmacology (Berl) 174:512-524

Neumeister A, Hu XZ, Luckenbaugh DA, Schwarz M, Nugent AC, Bonne O, Herscovitch P, Goldman D, Drevets WC, Charney DS (2006) Differential effects of 5-HTTLPR genotypes on the behavioral and neural responses to tryptophan depletion in patients with major depression and controls. Arch Gen Psychiatry 63:978-986
Nishizawa S, Benkelfat C, Young SN, Leyton M, Mzengeza S, de Montigny C, Blier P, Diksic M (1997) Differences between males and females in rates of serotonin synthesis in human brain. Proc Natl Acad Sci U S A 94:5308-5313

Nuller JL, Ostroumova MN (1980) Resistance to inhibiting effect of dexamethasone in patients with endogenous depression. Acta Psychiatr Scand 61:169-177

Owens MJ, Nemeroff CB (1994) Role of serotonin in the pathophysiology of depression: focus on the serotonin transporter. Clin Chem 40:288-295

Paelecke-Habermann Y, Pohl J, Leplow B (2005) Attention and executive functions in remitted major depression patients. J Affect Disord 89:125-135

Peters ML, Godaert GL, Ballieux RE, van Vliet M, Willemsen JJ, Sweep FC, Heijnen CJ (1998) Cardiovascular and endocrine responses to experimental stress: effects of mental effort and controllability. Psychoneuroendocrinology 23:1-17

Porter RJ, Gallagher P, Watson S, Young AH (2004) Corticosteroidserotonin interactions in depression: a review of the human evidence. Psychopharmacology (Berl) 173:1-17

Porter RJ, Gallagher P, Thompson JM, Young AH (2003) Neurocognitive impairment in drug-free patients with major depressive disorder. Br J Psychiatry 182:214-220

Richell RA, Deakin JF, Anderson IM (2005) Effect of acute tryptophan depletion on the response to controllable and uncontrollable noise stress. Biol Psychiatry 57:295-300

Riedel WJ, Klaassen T, Deutz NE, van Someren A, van Praag HM (1999) Tryptophan depletion in normal volunteers produces selective impairment in memory consolidation. Psychopharmacology (Berl) 141:362-369

Rinck M, Becker ES (2005) A comparison of attentional biases and memory biases in women with social phobia and major depression. J Abnorm Psychol 114:62-74

Roiser JP, Muller U, Clark L, Sahakian BJ (2007) The effects of acute tryptophan depletion and serotonin transporter polymorphism on emotional processing in memory and attention. Int $\mathrm{J}$ Neuropsychopharmacol 10:449-461

Rubinsztein JS, Rogers RD, Riedel WJ, Mehta MA, Robbins TW, Sahakian BJ (2001) Acute dietary tryptophan depletion impairs maintenance of "affective set" and delayed visual recognition in healthy volunteers. Psychopharmacology (Berl) 154:319-326

Ruhe HG, Mason NS, Schene AH (2007) Mood is indirectly related to serotonin, norepinephrine and dopamine levels in humans: a meta-analysis of monoamine depletion studies. Mol Psychiatry $12: 331-359$

Seckl JR, Fink G (1991) Use of in situ hybridization to investigate the regulation of hippocampal corticosteroid receptors by monoamines. J Steroid Biochem Mol Biol 40:685-688

Sheehan D, Lecrubier Y, Janavs J, Knapp E, Weiller E (1994) MINI International Neuropsychiatric Interview. University of South Florida, University of South Florida

Sobczak S, Honig A, Nicolson NA, Riedel WJ (2002a) Effects of acute tryptophan depletion on mood and cortisol release in firstdegree relatives of type I and type II bipolar patients and healthy matched controls. Neuropsychopharmacology 27:834-842

Sobczak S, Riedel WJ, Booij I, Aan Het Rot M, Deutz NE, Honig A (2002b) Cognition following acute tryptophan depletion: difference between first-degree relatives of bipolar disorder patients and matched healthy control volunteers. Psychol Med 32: 503-515

Sullivan PF, Neale MC, Kendler KS (2000) Genetic epidemiology of major depression: review and meta-analysis. Am J Psychiatry 157:1552-1562

Tavares JV, Drevets WC, Sahakian BJ (2003) Cognition in mania and depression. Psychol Med 33:959-967 
Van der Does AJ (2001) The effects of tryptophan depletion on mood and psychiatric symptoms. J Affect Disord 64:107-119

van der Veen FM, Evers EA, Deutz NE, Schmitt JA (2007) Effects of acute tryptophan depletion on mood and facial emotion perception related brain activation and performance in healthy women with and without a family history of depression. Neuropsychopharmacology 32:216-224

Van Praag HM (2004) Can stress cause depression? Prog Neuropsychopharmacol Biol Psychiatry 28:891-907

Van Praag HM, de Kloet ER, Van Os J (2004) Stress, the brain and depression. Cambridge University Press, Cambridge
Walderhaug E, Magnusson A, Neumeister A, Lappalainen J, Lunde H, Refsum H, Landro NI (2007) Interactive Effects of Sex and 5HTTLPR on Mood and Impulsivity During Tryptophan Depletion in Healthy People. Biol Psychiatry 62:593-599

Williams WA, Shoaf SE, Hommer D, Rawlings R, Linnoila M (1999) Effects of acute tryptophan depletion on plasma and cerebrospinal fluid tryptophan and 5-hydroxyindoleacetic acid in normal volunteers. J Neurochem 72:1641-1647

Young SN, Smith SE, Pihl RO, Ervin FR (1985) Tryptophan depletion causes a rapid lowering of mood in normal males. Psychopharmacology (Berl) 87:173-177 